\title{
Stem Cell Therapy for Avascular Necrosis of Femoral Head in Sickle Cell Disease: Report of 11 Cases and Review of Literature
}

\author{
Mir Sadat-Ali ${ }^{1}$, Md Q Azam², Ezzat M Elshabouri ${ }^{3}$, Ahmad M Tantawy ${ }^{1}$, Sadananda Acharya ${ }^{4}$ \\ ${ }^{l}$ Department of Orthopaedic Surgery, College of Medicine, Imam Abdulrahman Bin Faisal University, Dammam, Saudi Arabia \\ ${ }^{2}$ Department of Orthopaedic Surgery, King George Medical College and Hospital Lucknow, India \\ ${ }^{3}$ Department of Orthopaedic Surgery, King Fahad Hospital of the University, Al-Khobar, \\ ${ }^{4}$ Stem Cell Research, Institute for Research and Medical Consultations, Imam Abdulrahman Bin Faisal University, Dammam, Saudi Arabia
}

Background and Objective: Sickle cell disease (SCD) is quite common in eastern Saudi Arabia and Avascular necrosis of femoral head (ANFH) occurs in $30 \%$ of the young patients leading to early joint arthroplasty. This study was conducted to assess the benefits of injection of osteoblasts in the avascular lesions of the head of femur.

Patients and Methods: A preset technique was used, 10 CC of bone marrow aspiration was performed under local anesthesia and aseptic technique. Osteoblasts were separated from the bone marrow cells. The avascular area was drilled and 10 million osteoblasts were transplanted at the lesion site. Patients were seen in the out patient clinic after two weeks for removal of the suture and addressed the questionnaire and examined for the range of movement. The follow up MRI was performed at 4 months.

Results: The average age was $20.2 \pm 3.9$ years. The mean hemoglobin $S$ was $81.6 \pm 4.8$ percent. Quality of Life Score for Chronic Hip Disease was assessed and found at 8.6 ( 1 being the severe limitation and 10 being normal), whereas Harris hip score improved from $41.7 \pm 5.1$ to $88.93 \pm 3.6(p<0.001)$. MRI of pre and post osteoblast implantation showed robust new bone formation and disappearance of the avascular lesions.

Conclusions: The short term results were good and we believe the injection of osteoblast in the avascular lesion of head of femur is a less invasive procedure devoid of any untoward complications and merits such treatment in large patient group with longer follow up.

Keywords: Sickle cell disease, Avascular necrosis of head of femur, Osteoblasts, Stem cell therapy

Accepted for publication June 1, 2017, Published online November 30, 2017

Correspondence to Mir Sadat-Ali

Department of Orthopaedic Surgery, College of Medicine, Imam Abdulrahman Bin Faisal University, POBOX 40071, King Fahd Hospital of the University, Al-Khobar 31952, Saudi Arabia Tel: +966505848281, Fax: +966138820887

E-mail: smali@uod.edu.sa,drsadat@hotmail.com

(a) This is an open-access article distributed under the terms of the Creative Commons Attribution Non-Commercial License (http://creativecommons.org/ licenses/by-nc/4.0/), which permits unrestricted non-commercial use, distribution, and reproduction in any medium, provided the original work is properly cited.

Copyright (c) 2017 by the Korean Society for Stem Cells Research

\section{Introduction}

Sickle cell disease (SCD) is common in the eastern province of Saudi Arabia to the extent that gene frequency is reported in $17 \%$ of the population (1). Bone and joint bears the brunt of the disease with repeated attacks of vaso-occlusive crises and leading to devastating morbidity. Avascular necrosis of the femoral head (ANFH) occurs in about $30 \%$ of the population with early disability (2). Spontaneous recovery of the ANFH in SCD does not occur and majority end up in total hip arthroplasty (THA) for the reliefof pain $(3,4)$. Treatments like core decompression of the head of femur, osteotomies and anti-re- 
sorptives have been tried but results still remain unpredictable and disappointing $(5,6)$.

Hernigou et al. (7) reported a case with SCD in which they injected bone marrow concentrate in the avascular lesion of the humeral head with good result.

Pre-clinical and clinical studies have shown the efficacy of stem cells (SC) in the treatment of ANFH. Bone marrow concentrate, MSCs and bone marrow stromal cells (BMSCs) were used (8-11). The use of osteoblast injection and in general and particularly in SCD have not been reported. Here we report 11 patients with ANFH secondary to SCD who were injected with osteoblasts in the area of avascular lesion.

\section{Materials and Methods}

This is a prospective quasi-experiment study of SCD patients with ANFH. The inclusion criteria in this study was ANFH grade Ficat I and II and exclusion criteria was those patients who had more severe collapse (Ficat III and IV), who did not consented to be included in the study and those lived away from the catchment area of the eastern province for long follow up were excluded. The primary outcome measure was any change in the Harris Hip Score (HHS) and radiological changes of new bone formation in the MRI post injection. A preset technique was used, the first was the bone marrow aspiration. One gram of cefazolin IV was given pre-operatively. Patients were prepped and draped and $1 \%$ xylocaine $2 \mathrm{cc}$ was injected at the iliac crest close to anterior superior iliac spine. Before the aspiration needle was inserted patient received Intravenous tramadol $100 \mathrm{mg}$. Once $10 \mathrm{cc}$ of the marrow as aspirated and transferred to $5 \mathrm{cc}$ of Hyclone with antibiotic.

A sterile dressing was applied and patient was discharged after four hours.

The aspirate was layered on a Ficoll Paque (GE health Sciences, Uppsala, Sweden) solution and was subjected to a gradient centrifugation as per the manufacturer's instructions. The mononuclear cells thus separated were washed twice in ice cold phosphate buffered saline (PBS) before being seeded onto a T25 tissue culture flask in the presence of Human marrow stromal cell growth medium (Cell Applications, San Diego, USA). The medium was supplemented with penicillin-streptomycin at the rate of $100 \mathrm{IU} / \mathrm{ml}$ of Penicillin and $100 \mu \mathrm{g} / \mathrm{ml}$ of Streptomycin. The flasks were incubated in a $\mathrm{CO}_{2}$ incubator at $37^{\circ} \mathrm{C}$ with $5 \% \mathrm{CO}_{2}$ and $95 \%$ humidity for overnight. The unattached cells were washed off before a fresh medium was replenished for the expansion of attached cells. After over a week long culture, the stromal cells were expanded for another passage before being differentiated into osteoblasts. $\mathrm{hBM}-M S C$ s were seeded at the rate of $1 \times 103$ cells $/ \mathrm{cm}^{2}$ into a $9 \mathrm{~cm}$ cell culture dish in human osteoblast differentiation medium (Cell Applications, San Diego, USA). The culture was maintained in a $\mathrm{CO}_{2}$ incubator at $37^{\circ} \mathrm{C}$ with $5 \% \mathrm{CO}_{2}$ and $95 \%$ humidity. The medium was replenished every 5 th day till the end of 21 days of culture. At the end of 21 days, the cells were lifted off using $0.25 \%$ trypsin-EDTA with the help of cell scrapers, washed thrice in PBS, counted and re-suspended in normal saline solution for cell transplantation.

During the second procedure, the patients was put on supine on a fracture table. The patient was prepped and draped in the sterile fashion. Under the control of $\mathrm{C}$ arm the site of drilling was marked. Patients were given dormicom $2 \mathrm{mg}$ intravenous and fentanyl $1.5 \mathrm{mg} / \mathrm{kg}$ body weight and patients were maintained on on larangeal mask . Stab incision was made in the skin and subcutaneous tissue reaching till the bone. Using a $3 \mathrm{~mm}$ guide wire the site of the avascular area was penetrated and using $3.2 \mathrm{~mm}$ of cannulated drill bit over the guide wire the lesion was drilled. The drill was withdrawn by 2 centimeters and the patients position was change to the lateral position and the $1 \mathrm{ml}$ of osteoblasts in was injected through the cannulated drill and the leg was held in abduction for 5 minutes. The stab incision was closed by using $4 / 0$ nylon. Patient was transported to the day surgery recovery room in lateral decubitus and was discharged the same evening.

There were no peri-operative or post operative complications. Patients were seen in the out patient clinic after two weeks for removal of the suture and addressed the questionnaire and examined for the range of movement. The follow up MRI was performed at 4 months. A Students' "t" test was performed for HHS pre and post injection. To reach to a reasonable conclusion $10 \sim 15 \mathrm{pa}-$ tients are required for a quasi-experiment pretest and posttest evaluation (12). The study was approved by the ethical committee of the Department of orthopaedic Surgery and King Fahd Hospital of the University, Al-Khobar.

\section{Results}

Our 11 patients were female with average was $20.2 \pm 3.9$ years. The mean hemoglobin $S$ was $81.6 \pm 4.8$ percent and mean hemoglobin level $9.4 \pm 0.26 \mathrm{~g} / \mathrm{dl}$. Patients were seen at 2 weeks interval and evaluated and at three months the AS score for Quality of Life Score for Chronic Hip Disease was assessed and found at 8.6 ( 1 being the severe 
limitation and 10 being normal), whereas Harris hip score improved from $41.7 \pm 5.1$ to $88.93 \pm 3.6(\mathrm{p}<0.001)$. Patients were seen at 2 weeks interval and the suture was removed. At three months the AS score for Quality of Life Score for Chronic Hip Disease was assessed and found at 8.5 ( 1 being the severe limitation and 10 being normal) (13). The radiological evaluation using MRI significantly co-related the HHS and the AS score for Quality of Life Score for Chronic Hip Disease. MRI of pre and post osteoblast implantation (Fig. 1 3) patients. Table 1 gives the review of literature of 20 cases.

\section{Discussion}

We found that osteoblast injection at the site of the avascular lesion at the in SCD patients showed decreased of the daily the pain scale from 9 to 2 in all patients at 3 and 6 months after the injection. Secondly the radio- logical changes on the MRI showed marked improvement in with the new bone formation and reduction of the avascular area. Two previous studies in SCD patients have reported the results of bone marrow concentrate in 1 patient (8) and 8 patients by Daltro et al. (14) used autologous bone-marrow mononuclear cells implantation and found to be safe and suggested an efficacious treatment modality. Even though our patient number was small and we did not attempt to include FICAT III stage, but we did not carry out and decompression, still the results were encouraging.

Hernigou and Beaujean (15) used bone marrow concentrate as form of stem cell transplantation in the avascular area with standard core decompression gave excellent results at 5 years follow-up and only 9 of 145 hips requiring total hip arthroplasty (THA).

Two randomized controlled trials in non sickle cell disease patients compared core decompression alone versus
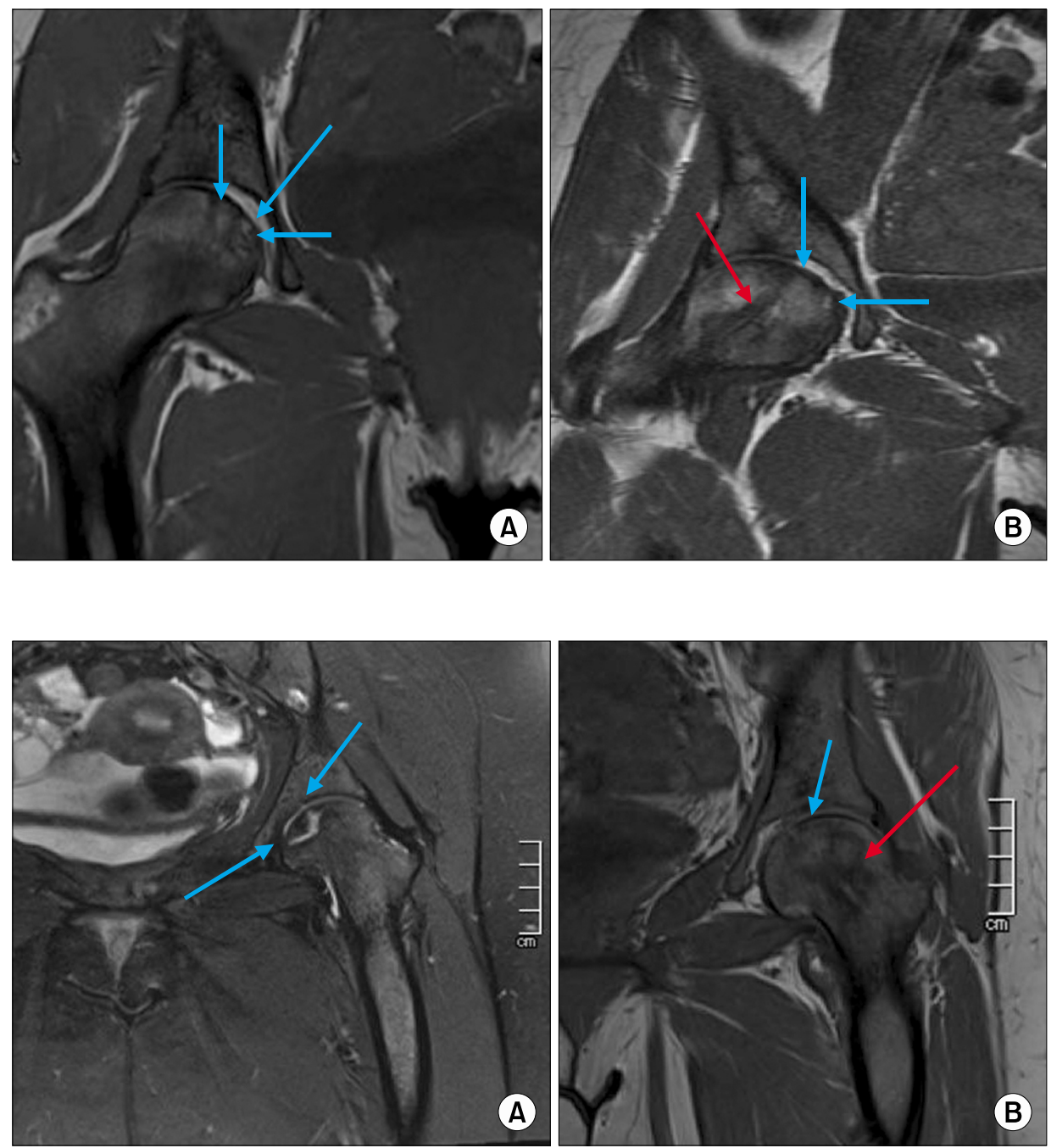

Fig. 1. (A) Pre-injection of Osteoblasts in right head of femur. Arrows showing avascular lesions. (B) Post injection of Osteoblasts at 4 months. The red arrow shows the tract. Through which the osteoblasts were injected.

Fig. 2. (A) Preoperatively MRI of 22 year old female patient with avascular necrosis of the head of femur. (B) Post injection of osteoblasts MRI after 4 months. New bone formation (blue arrow) and healing of the avascular area is clearly seen. The tract of the injection is highlighted in red Arrow. 

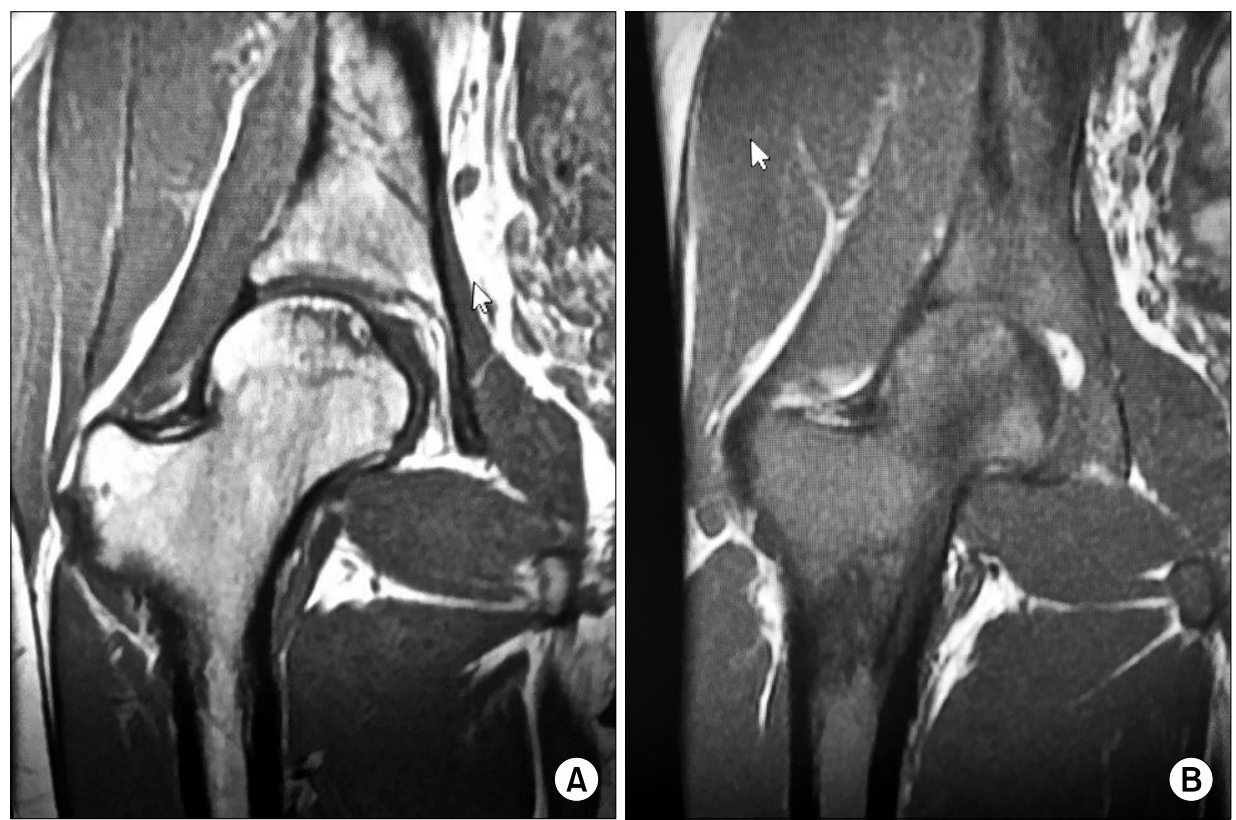

Fig. 3. (A) Pre- injection MRI of 19 year old female with changes in the head and neck of the femur, with avascular areas. (B) Post-Injection showing the remarkable comparative changes to Fig. 3A.

Table 1. Review of literature

\begin{tabular}{lccccccc}
\hline \multicolumn{1}{c}{ Authors } & $\begin{array}{c}\text { Number of } \\
\text { patients }\end{array}$ & $\begin{array}{c}\text { Average age } \\
\text { years }\end{array}$ & Site of lesion & Ficat stage & $\begin{array}{c}\text { Average } \\
\text { follow up } \\
\text { months }\end{array}$ & $\begin{array}{c}\text { HHS } \\
\text { Pre-operative }\end{array}$ & $\begin{array}{c}\text { HHS } \\
\text { Post-operative }\end{array}$ \\
\hline Hernigou et al. (7) & 1 & 13 & Humerus & NC & 48 & NA & NA \\
Daltro et al. (14) & 8 & $33 \pm 12.6$ & Femur & 0.87 & 5 & $78.5 \pm 6.2$ & $98.3 \pm 2.5$ \\
Present study & 11 & $20.2 \pm 3.9$ & Femur & 2 & 9 & $41.7 \pm 5.1$ & $88.93 \pm 3.6$ \\
\hline
\end{tabular}

HHS: Harris Hip Score.

core decompression with autologous bone marrow injection and found improvement in the Harris hip score and smaller number of patients going for joint arthoplasty $(11,16)$. These results and that of Daltro et al. (14) encouraged us to try stem cell therapy alternative to early THA in young patients. In our study we deviated from the reported procedure of standard core decompression with multiple drill holes and using bone marrow concentrate or BMMC and found our short term results to be better. Our reason for opting single $3.2 \mathrm{~mm}$ cannulated drill versus multiple drills was that with the later, higher chances of fracture and collapse of the head of femur and secondly instead of using BMMC or mesenchymal stem cells we used osteoblasts which could produce enough new bone within the 120 days life span of the implanted cells. Lastly we were reluctant to use MSCs as reduce the adverse effects of MSCs especially in the context of tumor modulation and malignant transformation of MSCs (17). In this study we had an initial short assessment of 4 months by means of subjective assessment by Harris Hip
Score and objective analysis of the MRI post injection. As the lifespan of osteoblasts is around 120 days any effect of new bone formation will be shown around four month period line.

The limitations of this study is that smaller number of patients but still within the required number for pretest and posttest assessment in same patients and statistical analyses may not be meaningful due to the lack of randomization and to limit this we tested only the HHS. The positive scenario of the procedure is that it will give the patients, pain free movements and better quality of life and delay the collapse of the head of femur requiring early THA. Since most of our patients are in and around 20 years of age, we believe our procedure was safe, minimally invasive and merits such treatment in large patient groups and longer follow up to clinically translate as a routine procedure.

\section{Potential conflict of interest}

The authors have no conflicting financial interest. 


\section{References}

1. El-Hazmi MAF, Warsy AS. Hemoglobinopathies in Arab countries. In: Teebi AS, Farag TI, editor. Genetic disorders among Arab populations. New York: Oxford University Press; 1997. 83-110

2. Sadat-Ali M. Avascular necrosis of the femoral head in sickle cell disease. An integrated classification. Clin Orthop Relat Res 1993;(290):200-205

3. Bozic KJ, Zurakowski D, Thornhill TS. Survivorship analysis of hips treated with core decompression for nontraumatic osteonecrosis of the femoral head. J Bone Joint Surg Am 1999;81:200-209

4. Iorio R, Healy WL, Abramowitz AJ, Pfeifer BA. Clinical outcome and survivorship analysis of core decompression for early osteonecrosis of the femoral head. J Arthroplasty 1998;13:34-41

5. Hungerford DS. Pathogenesis of ischemic necrosis of the femoral head. Instr Course Lect 1983;32:252-260

6. Luo RB, Lin T, Zhong HM, Yan SG, Wang JA. Evidence for using alendronate to treat adult avascular necrosis of the femoral head: a systematic review. Med Sci Monit 2014;20:2439-2447

7. Hernigou P, Bernaudin F, Reinert P, Kuentz M, Vernant JP. Bone-marrow transplantation in sickle-cell disease. Effect on osteonecrosis: a case report with a four-year follow-up. J Bone Joint Surg Am 1997;79:1726-1730

8. Yoshioka T, Mishima H, Akaogi H, Sakai S, Li M, Ochiai N. Concentrated autologous bone marrow aspirate transplantation treatment for corticosteroid-induced osteonecrosis of the femoral head in systemic lupus erythematosus. Int Orthop 2011;35:823-829

9. Lee HS, Huang GT, Chiang H, Chiou LL, Chen MH,
Hsieh CH, Jiang CC. Multipotential mesenchymal stem cells from femoral bone marrow near the site of osteonecrosis. Stem Cells 2003;21:190-199

10. Li ZH, Liao W, Cui XL, Zhao Q, Liu M, Chen YH, Liu TS, Liu NL, Wang F, Yi Y, Shao NS. Intravenous transplantation of allogeneic bone marrow mesenchymal stem cells and its directional migration to the necrotic femoral head. Int J Med Sci 2011;8:74-83

11. Sen RK, Tripathy SK, Aggarwal S, Marwaha N, Sharma RR, Khandelwal N. Early results of core decompression and autologous bone marrow mononuclear cells instillation in femoral head osteonecrosis: a randomized control study. J Arthroplasty 2012;27:679-686

12. Axelrod DA, Hayward R. Nonrandomized interventional study designs (Quasi-experimental designs). In: Penson DF, Wei JT, editor. Clinical research methods for surgeons. New York: Humana Press Inc.; 2006. 63-76

13. Azam MQ, Sadat-Ali M. Early cementless total hip arthroplasty in young sickle cell patients: $4-12$ year follow up. J Arthoplasty 2016;31:2536-2541

14. Daltro GC, Fortuna VA, Salvino de Araújo MA, Lessa PIF, Sobrinho UAB, Borojevic R. Femoral head necrosis treatment with autologous stem cells in sickle cell disease. Acta Ortop Bras 2008;16:23-27

15. Hernigou P, Beaujean F. Treatment of osteonecrosis with autologous bone marrow grafting. Clin Orthop Relat Res 2002;(405):14-23

16. Gangji V, De Maertelaer V, Hauzeur JP. Autologous bone marrow cell implantation in the treatment of non-traumatic osteonecrosis of the femoral head: five year follow-up of a prospective controlled study. Bone 2011;49:1005-1009

17. Wong RSY. Mesenchymal stem cells: angels or demons? J Biomed Biotechnol 2011 doi:10.1155/2011/459510 